archives

of thermodynamics

Vol. 38(2017), No. 4, 29-51

DOI: $10.1515 /$ aoter-2017-0023

\title{
Modeling of KERENA emergency condenser
}

\author{
RAFAŁ BRYK $\mathbf{K}^{a, b *}$ \\ HOLGER SCHMIDT ${ }^{b}$ \\ THOMAS MULL ${ }^{b}$ \\ THOMAS WAGNER ${ }^{b}$ \\ INGO GANZMANN ${ }^{b}$ \\ OLIVER HERBST ${ }^{b}$
}

a Warsaw University of Technology, Institute of Heat Engineering, Nowowiejska 21/25, 00-665 Warszawa, Poland

${ }^{b}$ AREVA GmbH, Paul-Gossen-Strasse 100, 91052 Erlangen, Germany

\begin{abstract}
KERENA is an innovative boiling water reactor concept equipped with several passive safety systems. For the experimental verification of performance of the systems and for codes validation, the Integral Test Stand Karlstein (INKA) was built in Karlstein, Germany. The emergency condenser (EC) system transfers heat from the reactor pressure vessel (RPV) to the core flooding pool in case of water level decrease in the RPV. EC is composed of a large number of slightly inclined tubes. During accident conditions, steam enters into the tubes and condenses due to the contact of the tubes with cold water at the secondary side. The condensed water flows then back to the RPV due to gravity. In this paper two approaches for modeling of condensation in slightly inclined tubes are compared and verified against experiments. The first approach is based on the flow regime map. Depending on the regime, heat transfer coefficient is calculated according to specific semi-empirical correlation. The second approach uses a general, fully-empirical correlation. The models are developed with utilization of the object-oriented Modelica language and the open-source OpenModelica environment. The results are compared with data obtained during a large scale integral test, simulating loss of coolant accident performed at Integral Test Stand Karlstein (INKA). The comparison shows a good agreement.
\end{abstract}

\footnotetext{
*Corresponding Author. Email rafal.bryk@areva.com
} 
Due to the modularity of models, both of them may be used in the future in systems incorporating condensation in horizontal or slightly inclined tubes. Depending on his preferences, the modeller may choose one-equation based approach or more sophisticated model composed of several exchangeable semi-empirical correlations.

Keywords: Condensation; Kerena; Emergency condenser; Modelica; OpenModelica

\section{Nomenclature}

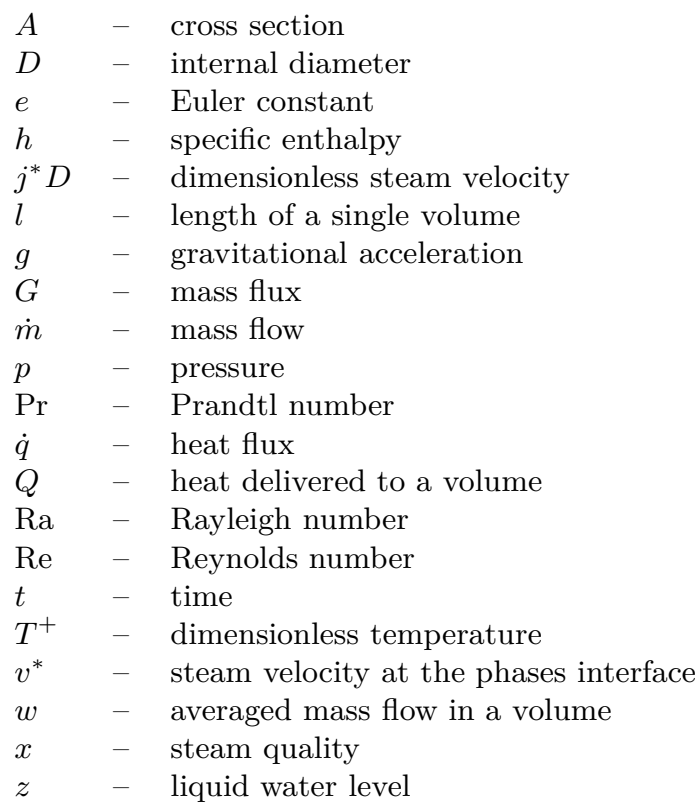

\section{Greek symbols}

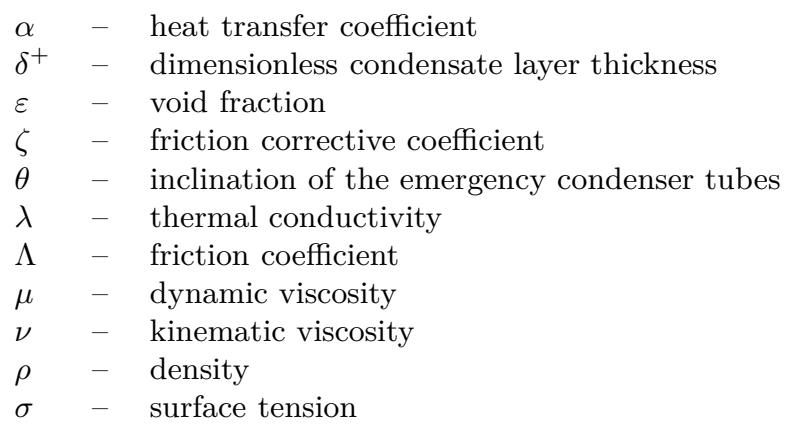

\section{Subscripts}

a - pressure drop due to acceleration

av - average value 


\begin{tabular}{|c|c|c|}
\hline Ann_lam & - & annular laminar flow \\
\hline Ann_tur & - & annular turbulent flow \\
\hline Ann_wave & - & Annular wavy flow \\
\hline$a v$ & - & average value \\
\hline$B S P \_l a m$ & - & bubble, plug, slug flow laminar \\
\hline$B S P \_t u r$ & - & bubble, plug, slug flow turbulent \\
\hline crit & - & critical value of Reynolds number \\
\hline$f$ & - & pressure drop due to friction \\
\hline$F i$ & - & film \\
\hline$h$ & - & derivative with constant enthalpy \\
\hline$j$ & - & number of node \\
\hline$k$ & - & number of volume \\
\hline$L$ & - & liquid \\
\hline $\mathrm{Nu}$ & - & according to Nusselt \\
\hline $\operatorname{mix}$ & - & mixture \\
\hline$p$ & - & derivative with constant pressure \\
\hline$s$ & - & saturation \\
\hline$S P h$ & - & single phase \\
\hline Spray & - & spray flow regime \\
\hline Strat & - & stratified flow regime \\
\hline$T P$ & - & two phase \\
\hline$V$ & - & vapour \\
\hline$w$ & - & wall \\
\hline
\end{tabular}

\section{Introduction}

Currently, nuclear power plants provide over $11 \%$ of the world's electricity. In 30 countries all over the world, there is 448 operational reactors, 76 of which are boiling water reactors (BWR) [1]. A vast majority of the operational BWRs are generation II reactors. An important system for a proper reactor core protection is the emergency core-cooling system. Its purpose is to prevent the core from overheating either by maintaining the water level in the reactor pressure vessel (RPV) at an appropriate level or by flooding the core with coolant, when maintaining of the water level is not possible.

In general, BWRs under operation are equipped with two different types of emergency cooling systems. These are: high-pressure systems and lowpressure systems.

The purpose of high-pressure systems is to inject substantial quantities of water into the reactor when the water level decreases and the reactor is still at high pressure. The system is usually powered by steam from the reactor. Should the water level could not be maintained with the system, the next systems respond.

Low-pressure systems are activated after depressurization of the RPV. 
These systems have larger capacity than the high-pressure systems and the coolant is supplied from several, redundant power sources. Thus, the lowpressure core spray system and low-pressure coolant injection system may be distinguished. The first one delivers water from the top of the RPV. The system collapses steam above the core, what - apart from cooling has also an impact on RPV pressure reduction. The second low-pressure system consists of several pumps and it is designed as an emergency mode of the residual heat removal (RHR) system.

All the above systems are proven and verified during decades of operation of existing power plants. However, they need an external power supply. The most often, this power is delivered from a turbine, combustion engine or an electrical motor. The modern approach for nuclear reactors design is to avoid the necessity of external power supply and to equip reactors with passive safety systems. These systems are automatically triggered and they function according to basic laws of physics such as gravity and natural convection. By combining these passive systems with proven active systems, the advanced reactors of generation III/III+ are undoubtedly the safest ever developed.

In order to elaborate the BWR product line, AREVA in collaboration with German nuclear utilities and with support from European partners developed a new BWR design - KERENA - a medium-capacity boiling water reactor [2].

Figure 1 shows a cross section through the containment of KERENA. The reactor utilizes several innovative passive safety systems which ensure safe depressurization and heat removal in case of emergency or accidents, including loss of coolant accident (LOCA). The main components of KERENA passive safety features are containment cooling condenser (CCC), emergency condenser (EC), passive pressure pulse transmitters (PPPT) and passive core flooding system. These systems utilize basic physical laws such as gravity and free convection. Therefore, in order to operate them, there is no need for an external power supply and additional devices like pumps. This in turn leads to strong reduction of costs during construction of the plant.

In order to examine performance of the passive systems, a dedicated test facility was built at the Components Testing Department of AREVA in Karlstein, Germany. The Integral Test Facility Karlstein (INKA) represents the KERENA containment with a volume scaling of 1:24. Components heights and levels over the ground are kept in the full scale. The test 


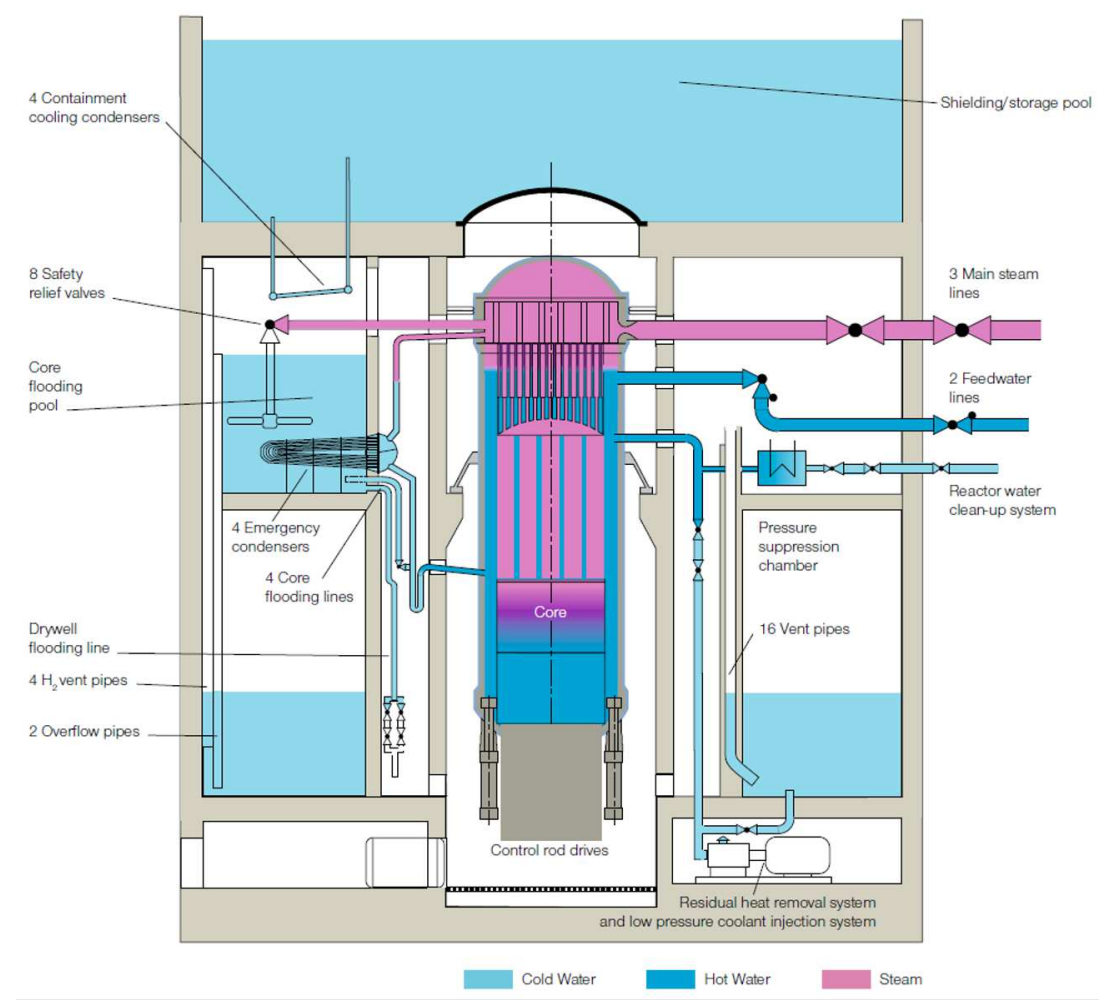

Figure 1: Cross section through the containment of KERENA.

rig setup allows to investigate both, each component individually and the whole system during integral tests. For the purpose of testing the integral system, INKA is equipped with several large vessels corresponding to individual pools and vessels of KERENA. The reactor pressure vessel (RPV) is represented by the steam accumulator of the Karlstein large valve test facility GAP (Gross Armatures Prüfstand). The vessel has a storage capacity of $1 / 6$ of the KERENA RPV. In order to simulate the decay heat of the core, the vessel is fed with steam by Benson boiler with maximum power output of $22 \mathrm{MW}$. The vessel is designed for operation pressure up to 16 MPa. Compartments of the KERENA RPV are represented by separate vessels: flooding pool vessel, pressure suppression pool vessel and drywell vessel. An additional tank is used as a representation of shielding/storage pool vessel.

Due to the appropriate instrumentation concept and the density of sen- 
sors, data obtained during experiments performed at the facility may be utilized for validation of thermal-hydraulic codes. Therefore, measurements collected during one of the tests performed in the framework of the integral experimental and analytical safety cases for design-basis accidents featuring passive systems were used to validate condensation models developed in open source OpenModelica Connection Editor environment utilizing the Modelica language.

Modelica is a non-proprietary, object-oriented, equation-based language to conveniently model complex physical systems [3]. There are several environments which utilize the language. Models described in this paper were developed with OpenModelica Connection Editor - an open-source environment developed by Open Source Modelica Consortium for industrial and academic usage [4]. Modelica is equipped with a large multi-domain, opensource library. Components encapsulated in the library may be developed, enhanced and their features may be inherited by other objects.

\section{Operation of KERENA emergency condenser}

The main purposes of the Emergency Condenser is heat removal and depressurization of the RPV in abnormal conditions. The principle of the EC operation is presented in Fig. 2.

The emergency condenser is composed of a large number of slightly inclined tubes. The tubes are submerged in the core flooding pool and they are filled with water during regular operation of the plant. Should the water level in the RPV decrease, the water drains from the tubes and the steam from the RPV enters the EC tubes. Due to the contact of tube walls with the cold water at the secondary side in the core flooding pool, heat transfer occurs leading to condensation of steam in tubes. Since the tubes of the emergency condenser are slightly inclined, the condensate flows back to the RPV due to gravity. The emergency condenser is connected to the RPV without any isolating elements and it comes into action automatically without any need for electric power. Thus, the device is operated according to the natural law of communicating vessels. 


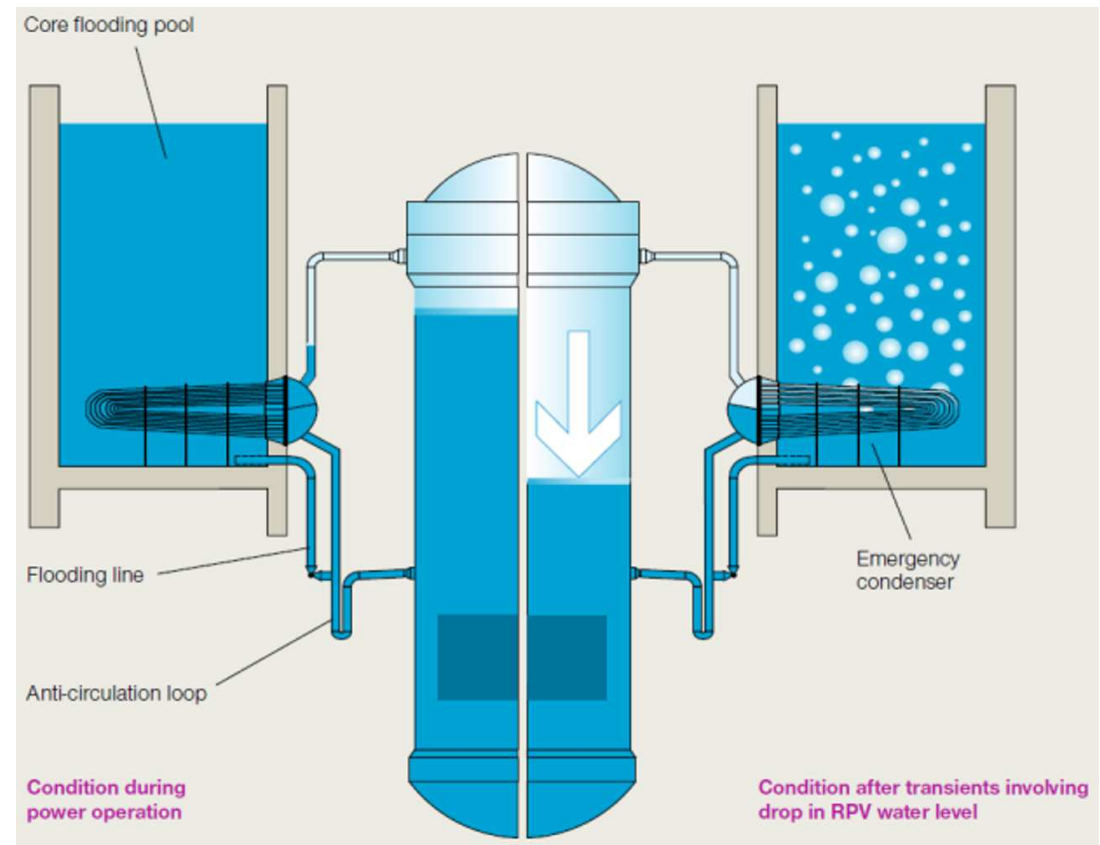

Figure 2: Operation scenarios of the emergency condenser.

\section{Models development}

\subsection{System description and governing equations}

The analysed system was a straight pipe slightly inclined to the horizontal orientation and a vessel filled with liquid water up to a certain level. The volume over the water surface was filled with the ideal gas.

The tube inclination was $1.3 \%$ and its length was $10.8 \mathrm{~m}$. The inner diameter was $48.3 \times 2.5 \mathrm{~mm}$. The volume of the vessel was $210 \mathrm{~m}^{3}$ and its diameter was $5 \mathrm{~m}$. At the beginning, the water level in the vessel was $7.8 \mathrm{~m}$.

The flow through the pipe is governed by the mass, energy and momentum conservation equations, as one-dimensional, partial differential equations. In the vessel the liquid water phase and ideal gas were distinguished. In the system the following assumptions were applied:

- uniform velocity is assumed on a cross section of the tube,

- longitudinal heat diffusion term in the tube is neglected, 
- accumulation is considered in each control volume of the tube,

- influence of the angulation of the EC pipes is neglected,

- thermal-hydraulic properties of the fluid in the tube are calculated on the basis of pressure and enthalpy at each node,

- tube wall is assumed to have constant thermal conductivity,

- tube bundle influence is not taken into account,

- boundary conditions are assumed according to the measurements and initial conditions of the experiment,

- heat transfer coefficient at the secondary side is taken into account and calculated according to correlation for free convection in a pool of single-phase liquid water;

- liquid water in the vessel is modelled as an expandable medium so its volume increases with temperature,

- gas in the vessel is modelled as the ideal gas,

- heat transfer between liquid water and the gas is modelled as a linear function of the temperature difference between the mediums,

- there is no mass transfer between water and gas phases.

Figure 3 shows the diagram view of the object-oriented configuration of the model.

The pipe model was set up by adopting an extended version of the Flow1DFV2ph component of the Modelica ThermoPower library. The model was discretised and divided into 20 volumes. The component, in which the balance equations are discretized by means of the finite volume approach was modified by formulation of momentum balance equation for each volume instead of the whole component. This lead to more detailed description by enabling calculation of fluid properties and saturation conditions at each node taking into account pressure at a particular node. Before modification, fluid properties at each node were evaluated either with respect to inlet or outlet pressure.

The mass balance equation in each volume of the pipe is given by

$$
\dot{m}_{j}-\dot{m}_{j+1}=A l \frac{d \rho_{k}}{d t} .
$$

Taking pressure and specific enthalpy as state variables

$$
\dot{m}_{j}-\dot{m}_{j+1}=A l\left[\left(\frac{\partial \rho_{k}}{\partial h_{k}}\right)_{p} \frac{d h_{k}}{d t}+\left(\frac{\partial \rho_{k}}{\partial p_{j}}\right)_{h} \frac{d p_{j}}{d t}\right] .
$$




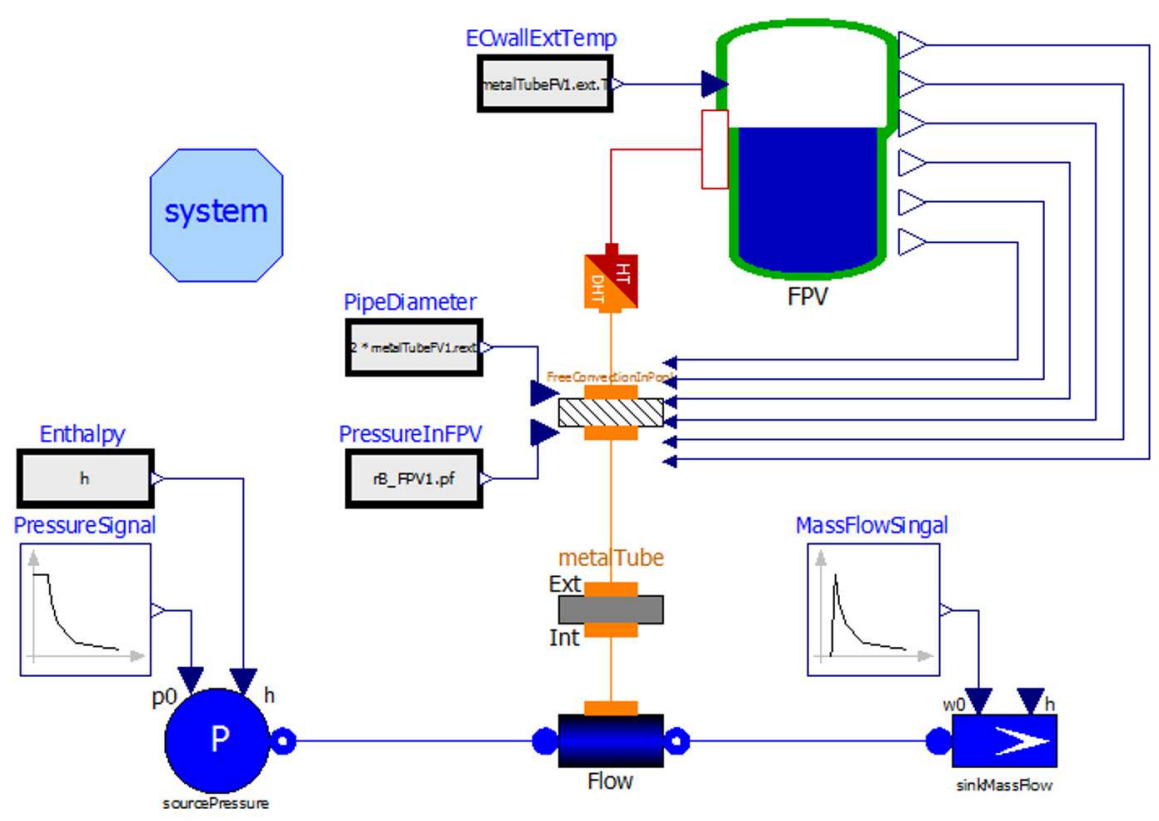

Figure 3: Diagram view of the model.

The energy balance equation in each volume of the pipe is given by

$$
\dot{m}_{j} h_{j}-\dot{m}_{j+1} h_{j+1}+Q_{k}=A l\left(\rho_{k} \frac{d h_{k}}{d t}-\frac{d p_{k}}{d t}\right) .
$$

The momentum balance equation for each volume of the pipe is given by

$$
p_{j}-p_{j+1}=\frac{l}{A} \frac{d w_{k}}{d t}+\rho_{k} g l \sin \theta+\triangle p_{k,} \quad f+\triangle p_{k, a},
$$

with acceleration and friction pressure losses for each volume given by

$$
\begin{gathered}
\triangle p_{k, a}=\frac{1}{A^{2}} w_{k}^{2}\left(\frac{1}{\rho_{j+1}}-\frac{1}{\rho_{j}}\right), \\
\triangle p_{k, f}=\zeta \frac{2 \Lambda_{k} l}{D A^{2} \rho_{k}} w_{k}^{2},
\end{gathered}
$$

where $\Lambda_{k}$ is calculated with Colebrook correlation:

$$
\Lambda_{k}=\frac{0.332}{\ln \left(\frac{e}{3.7}+\frac{5.47}{\operatorname{Re}_{k}^{0.9}}\right)^{2}} .
$$


In Eqs. (1)-(7) $A$ and $l$ stand respectively for tube cross section and length of a single volume. Subscript $k$ denotes volume number while $\mathrm{j}$ stands for number of node. Subscripts $p$ and $h$ mean derivatives with constant pressure and enthalpy respectively.

In the flow model a replaceable module for heat transfer calculation was introduced. This allowed to call different models of heat transfer developed as separate objects.

In order to model the heat exchange, new heat transfer components were introduced so that to implement correlations expressing two approaches described in subsections 3.2 and 3.3. These models were then called in the flow model by redeclare model clause in the text view of the whole system model presented as diagrams in Fig. 3.

Additionally, a call of a function for calculation of void fraction was implemented into the standard Flow1DFV2ph component. The void fraction was calculated according to analytical heterogeneous momentum flux approach.

The Flooding Pool Vessel model was developed from basics. It takes into account expandability of water due to temperature increase and its influence on the pressure in the vessel. Properties of water in the FPV are delivered to the heat transfer component (placed between the pipe and the vessel in Fig. 3) which calculates the heat transfer coefficient at the secondary side.

In the FPV model there is no water mass flowing into or out from the vessel, so the mass conservation equation is given by

$$
\rho_{l} A \frac{d z}{d t}+A z \frac{d \rho_{l}}{d t}=0,
$$

where $z$ is the water level. The energy balance equation for liquid in the FPV is given by

$$
\rho_{l} V_{l} \frac{d h_{l}}{d t}-V_{l} \frac{d p}{d t}-p \frac{d V_{l}}{d t}=-Q_{\text {surface }}+Q_{E C} .
$$

In the equation above, $\mathrm{Q}_{E C}$ is the power of $\mathrm{EC}$ and $\mathrm{Q}_{\text {surface }}$ is the heat exchange between liquid water and gas given as a linear function of temperature difference.

The mass of gas is constant in the vessel and it is given by:

$$
m_{g}=V_{g} \rho_{g}
$$


The energy balance for gas is given by

$$
\rho_{g} V_{g} c_{p g} \frac{d T_{g}}{d t}=V_{g} \frac{d p_{g}}{d t}+Q_{\text {surface }} .
$$

To the gas volume applies also the Clapeyron equation

$$
p_{g}=\rho_{g} R T_{g},
$$

where $R$ is the specific gas constant for air.

\subsection{Flow regime map based model of condensation}

The flow regime map based model was developed utilizing the map proposed by Tandon [9]. The model calculates the average at particular regime heat transfer coefficient by switching between several flow regime dependent semi-empirical correlations. Figure 4 illustrates different flow patterns in horizontal tube. The flow regime map, together with correlations applied in specific regime is shown in Fig. 5.

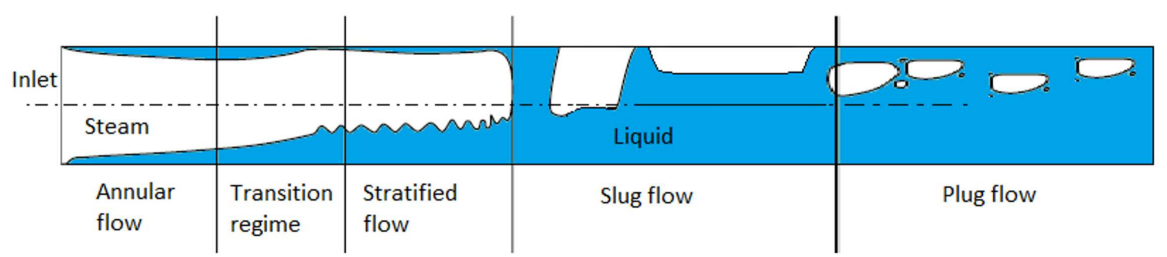

Figure 4: Flow patterns during condensation in horizontal tubes [5].

Tandon's flow regime map is based on the volume ratio of liquid and gas in a cross section area $(1-\varepsilon) / \varepsilon$, where $\varepsilon$ stands for the void fraction, and on the dimensionless steam velocity

$$
j_{D}^{*}=\frac{x G}{\left[g D \rho_{V}\left(\rho_{L}-\rho_{V}\right)\right]^{0.5}} .
$$

Since the EC pipes are initially filled with liquid water and due to possible single-phase condensate flow at the lower sections of the tube, an additional correlation for single phase liquid water flow was implemented into the model. Table 1 indicates all correlations and application ranges. In the table subscripts $F i$ and $V$ indicate whether a variable refers to condensate film or vapour. Further details of different patterns formation development of the correlations can be found in [8-16]. 


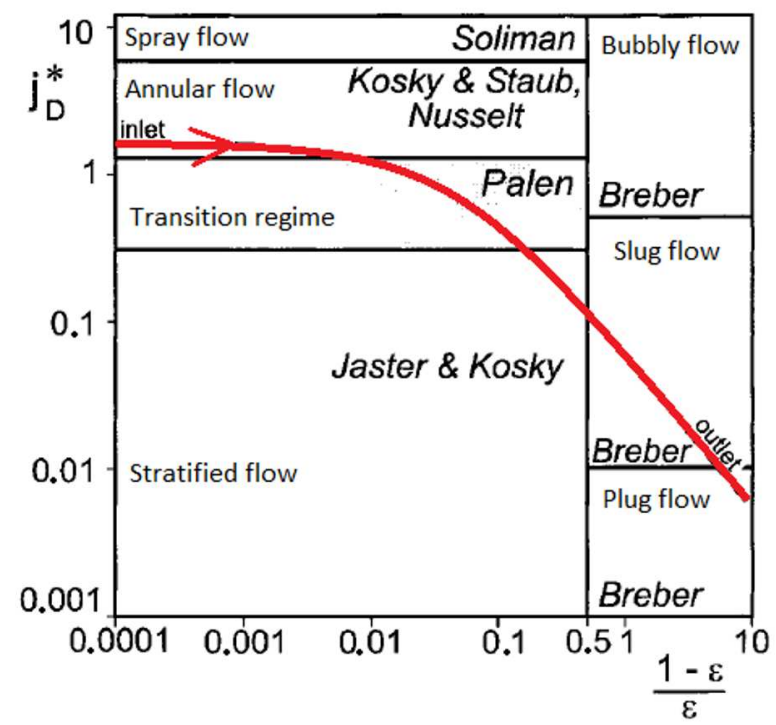

Figure 5: Tandon's flow regime map [5].

\subsection{General correlation model of condensation}

The implemented general correlation for condensation in horizontal tubes was developed by Shah [17]:

$$
\begin{gathered}
\alpha=\alpha_{S P h}\left[(1-x)^{0.8}+\frac{3.8 x^{0.76}(1-x)^{0.04}}{p_{r}^{0.38}}\right], \\
\alpha_{S P h}=0.023 \operatorname{Re}_{L}^{0.8} \operatorname{Pr}_{L}^{0.4} \frac{\lambda}{D} .
\end{gathered}
$$

The correlation was developed by analysis of a wide variety of experimental data. This includes different fluids and pipe orientations. Details of the correlation development may be found in [17].

\subsection{Free convection modelling at the secondary side}

In order to obtain a full picture of the performance of EC model, it is necessary to take into account the secondary side of the device. In the KERENA design, the EC tubes are submerged in the cold water of the flooding pool vessel. Thus, when the EC comes into action during accidental conditions, 
Table 1: Heat transfer correlations with respect to flow regime.

\begin{tabular}{|c|c|c|c|}
\hline $\begin{array}{l}\text { Flow } \\
\text { regime }\end{array}$ & Correlation & Range of application & Further details of calculations \\
\hline $\begin{array}{l}\text { Annular } \\
\text { laminar [8] }\end{array}$ & $\begin{array}{l}\alpha_{A n n_{-} l a m} \\
=1.1025 \lambda_{F i} \operatorname{Re}_{F i}^{-0.33}\left[\frac{\rho_{F i}\left(\rho_{F i}-\rho_{V}\right) g}{\mu_{F i}^{2}}\right]^{0.33}\end{array}$ & $\begin{array}{c}1 \leq j_{D}^{*} \leq 6 \text { and } \frac{1-\varepsilon}{\varepsilon} \leq 0.5 \\
\operatorname{Re}_{F i}<\operatorname{Re}_{\text {wave }}\end{array}$ & $\begin{array}{c}\operatorname{Re}_{F i}=\frac{(1-x) G D}{\mu_{F i}} \\
\operatorname{Re}_{\text {wave }}=0.392\left[\left(\frac{\sigma}{\rho_{F i} g}\right)^{0.5}\left(\frac{g}{v_{F i}^{2}}\right)^{0.33}\right]^{0.75}\end{array}$ \\
\hline $\begin{array}{l}\text { Annular } \\
\text { wavy [12] }\end{array}$ & $\alpha_{\text {Ann_wave }}=0.8 \mathrm{Re}_{F i}^{0.11} * \alpha_{\mathrm{Nu}}$ & $\begin{aligned} & 1 \leq j_{D}^{*} \leq 6 \text { and } \frac{1-\varepsilon}{\varepsilon} \leq 0.5 \\
& \operatorname{Re}_{\text {wave }}<\operatorname{Re}_{F i}<\operatorname{Re}_{\text {crit }}\end{aligned}$ & $\operatorname{Re}_{\text {crit }}=\frac{100}{\operatorname{Pr}_{F i}}$ \\
\hline $\begin{array}{l}\text { Annular } \\
\text { turbulent } \\
{[13]}\end{array}$ & $\alpha_{A n n_{-} \text {tur }}=\frac{\rho_{F i} v^{*} c_{p, F i}}{T^{+}\left(\delta^{+}\right)}$ & $\begin{array}{c}1 \leq j_{D}^{*} \leq 6 \text { and } \frac{1-\varepsilon}{\varepsilon} \leq 0.5 \\
\operatorname{Re}_{c r i t}<\operatorname{Re}_{F i}\end{array}$ & $\begin{array}{c}\delta^{+}=0.0504\left(0.5 \operatorname{Re}_{F i}\right)^{0.5} \text { for } \operatorname{Re}_{F i}<1000 \\
\delta^{+}=0.0504\left(\operatorname{Re}_{F i}\right) \\
T^{+}\left(\delta^{+}\right)=\delta^{+} \operatorname{Pr}_{F i} \text { for } \operatorname{Re}_{F i} \geq 1000 \\
T^{+} \leq 5 \\
T^{+}\left(\delta^{+}\right)=5\left[\operatorname{Pr}_{F i}+\ln \left(1+\operatorname{Pr}_{F i}\left(0.2 \delta^{+}-1\right)\right)\right] \text { for } 5 \\
<\delta^{+}<30 \\
T^{+}\left(\delta^{+}\right)=5\left[\operatorname{Pr}_{F i}+\ln \left(1+5 \operatorname{Pr}_{F i}\right)\right. \\
\left.+0.495 \ln \left(\frac{1}{30} \delta^{+}\right)\right] \text {for } \delta^{+} \\
>30 \\
v^{*}=\sqrt{\frac{D}{4 \rho_{F i}}\left(\frac{d p}{d x}\right)_{f r i c, T P}}\end{array}$ \\
\hline $\begin{array}{l}\text { Stratified } \\
{[8]}\end{array}$ & $\alpha_{\text {Strat }}=\varepsilon^{0.75} * \alpha_{\text {Ann_lam }}$ & $j_{D}^{*}<1$ and $\frac{1-\varepsilon}{\varepsilon} \leq 0.5$ & \\
\hline $\begin{array}{l}\text { Bubble, } \\
\text { slug, plug } \\
\text { laminar } \\
{[15,16]}\end{array}$ & $\alpha_{B S P_{-} \text {lam }}=1.86 \frac{\lambda_{F i}}{D}\left(\operatorname{Re}_{F i} \operatorname{Pr}_{F i} \frac{D}{l}\right)^{0.33}\left(\frac{\mu_{F i}}{\mu_{w}}\right)^{0.14}$ & $\begin{array}{l}\frac{1-\varepsilon}{\varepsilon}>0.5 \\
\operatorname{Re}<2000\end{array}$ & \\
\hline $\begin{array}{l}\text { Bubble, } \\
\text { slug, plug } \\
\text { turbulent } \\
{[15,16]} \\
\end{array}$ & $\alpha_{B S P_{-} t u r}=0.024 \frac{\lambda_{F i}}{D}\left(\operatorname{Re}_{F i}^{0.8} \operatorname{Pr}_{F i}^{0.33}\right)\left(\frac{\mu_{F i}}{\mu_{w}}\right)^{0,14}$ & $\begin{array}{l}\frac{1-\varepsilon}{\varepsilon}>0.5 \\
\operatorname{Re} \geq 2000\end{array}$ & \\
\hline Spray [10] & $\begin{array}{l}\alpha_{\text {spray }} \\
=0.00345 \mathrm{Re}_{a v}^{0,9} \mathrm{Pr}^{0,33}\left(\frac{r}{c_{p, V}\left(T_{S}-T_{W}\right)}\right)^{-0.33}\end{array}$ & $j_{\dot{D}}>6$ and $\frac{1-\varepsilon}{\varepsilon} \leq 0.5$ & $\begin{array}{c}\mathrm{Re}_{a v}=\frac{G D}{\mu_{m i x}} \\
\mu_{m i x}=\frac{x}{\mu_{V}}+\frac{1-x}{\mu_{L}}\end{array}$ \\
\hline Single phase & $\alpha_{S P h}=0.023 \frac{\lambda}{D} \operatorname{Re}^{0.8} P r^{0.4}$ & $\varepsilon=0$ & \\
\hline
\end{tabular}


heat is transferred to the FPV. Possible heat transfer mechanisms at the secondary side are single-phase free convection or pool boiling. The second mechanism occurs when either the water temperature in the FPV or the heat flux is high enough. Experiments at the INKA test facility show that the bubble formation does not occur in the FPV during simulation of large loss of coolant due to main steam line break. Therefore, in the model of the secondary side only the correlation for free convection was included. However, the model is equipped with variables informing the user, if the conditions in the FPV are close to evaporation state, and hence, the influence of bubbles formation on the heat transfer coefficient should be taken into account. Following the VDI Heat Atlas [7], the adopted condition for boiling occurrence is the empirical equation developed by Bergles [18]:

$$
\left(T_{w}-T_{\text {sat }}\right)_{k}=\frac{5}{9}\left[\left(\frac{\dot{q}}{1120}\right)^{0.463} p_{k}^{-0.535}\right]^{p^{0.0234}} .
$$

In order to calculate the heat transfer coefficient at the secondary side, the correlation for external single-phase flow around horizontal cylinders was applied [19]:

$$
\mathrm{Nu}=\left\{0.6+0.387[\operatorname{Ra} f(\operatorname{Pr})]^{\frac{1}{6}}\right\}^{2} .
$$

The function $f(\operatorname{Pr})$ describes the effect of the Prandtl number over the entire range of $\mathrm{Pr}$ and is given by

$$
f(\operatorname{Pr})=\left[1+\left(\frac{0.559}{\operatorname{Pr}}\right)^{\frac{9}{16}}\right]^{-\frac{16}{9}}
$$

\section{Results}

Experimental data for models validation were obtained during simulation of the main steam line break (MSLB) with taking into account the decay heat. The test was performed at the INKA test facility in the framework of the EASY (Integral Experimental and Analytical Safety Cases for Design-Basis Accidents Featuring Passive Systems) Project. Since the MSLB experiment was conducted in order to investigate performance of the integral system rather than a single component, it should be emphasised, that other components like reactor pressure vessel, drywell vessel, pressure suppression pool, shielding/storage pool and standpipe strongly influenced behaviour of the 
emergency condenser. Furthermore, the test course assumed certain activities at certain time points, which lead to strong transients and backflows in the pipe in the volume occupied by steam and indisposed the comparison of results in steady states conditions.

As it may be concluded from Fig. 3, pressure applied to the system was given and at the inlet to the piping system. This pressure corresponds to the one measured in the RPV during the test which results from realising steam from RPV to the Dry Well. Figure 6 presents the pressure applied to the model which at the same time is the pressure measured in the RPV. The dashed and dotted lines illustrate measured and calculated pressure drops over the emergency condenser.

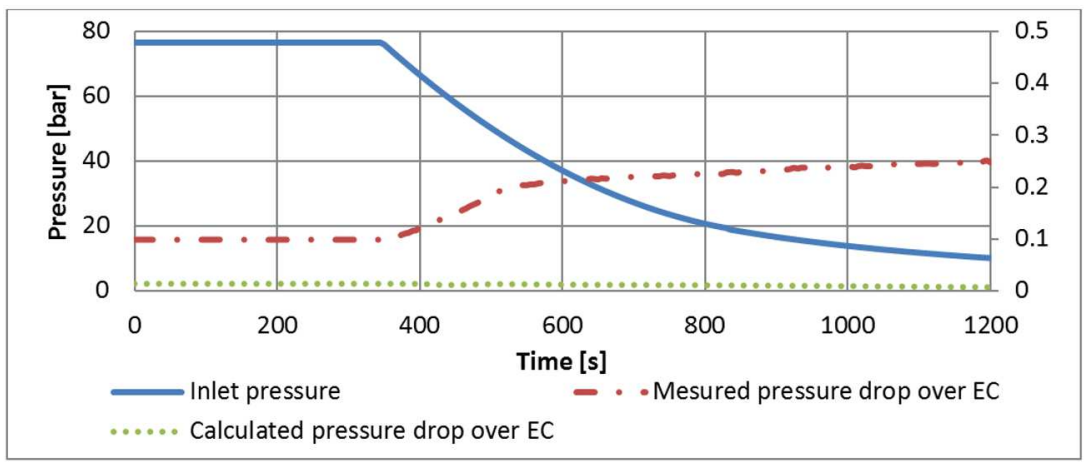

Figure 6: Inlet pressure and pressure drops over the EC.

The maximal value of the measured pressure drop over the EC is $0.025 \mathrm{MPa}$. The calculated value is lower. The discrepancy between the values of pressure drop comes from not taking into account the angulation of the EC tubes. The angulation introduces geodetic height of around $0.9 \mathrm{~m}$ which has an impact to the pressure difference between outlet and inlet of the tubes. Furthermore, insignificant value of the pressure drop comes from the fact, that some of the contributions of total pressure drop have positive and some negative values. This means that pressure drop due to friction is compensated by the pressure build-up due to negative acceleration of the fluid and inclination of the tubes.

Strong decrease of pressure in the RPV impacts mass flows at the inlet and outlet of the EC tubes. The outlet liquid water flow is mainly governed by the water level in the RPV, since EC and RPV operate as communicating vessels. The inlet flow is influenced by depressurisation of the RPV and consequent depressurization of the EC. This results in the steam mass 
flowing upward out of the EC at beginning of the pressure drop which results in turn in measurement of zero value. Measured and calculated mass flows are presented in Fig. 7.

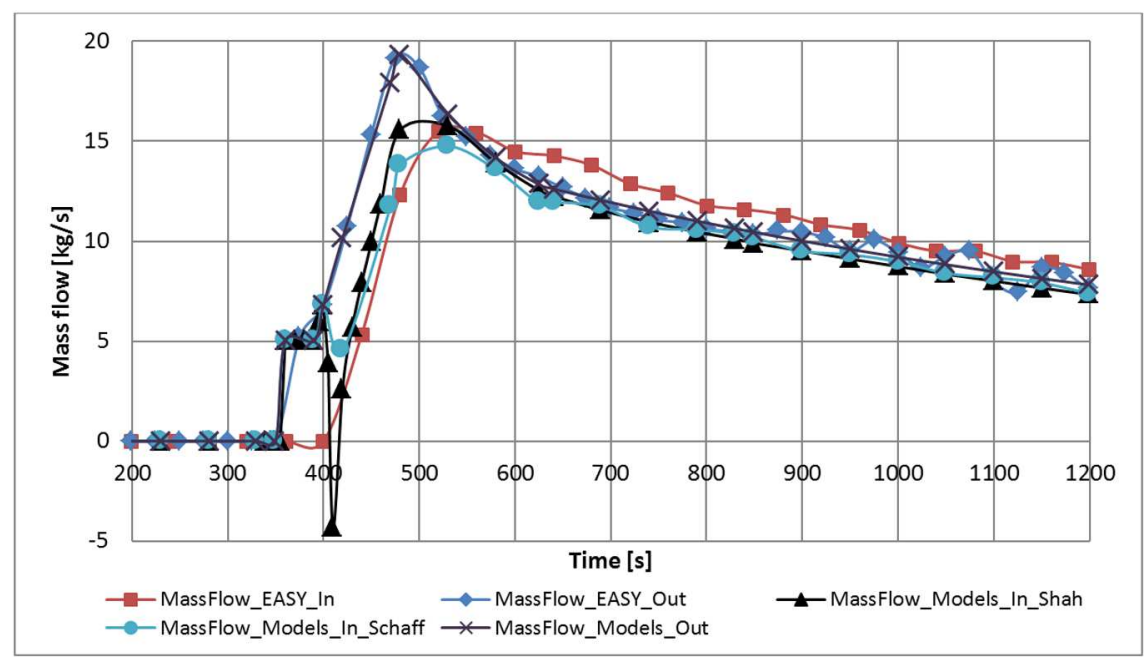

Figure 7: Measured and calculated mass flows.

Figure 7 shows that both models predicted the inlet mass flow peak with a good accuracy. The inlet mass flow according to flow regime based model is slightly lower. After 600 seconds both models calculate around $8 \%$ lower value of the inlet flow than the measured one. The measured water level in the RPV with reference to the middle of the EC is presented in Fig. 8.

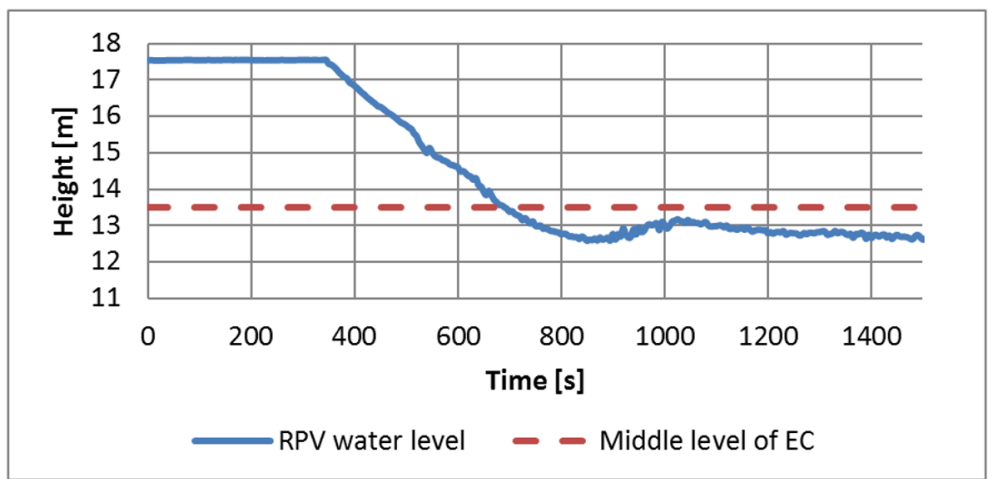

Figure 8: RPV water level and the middle level of the EC. 
The water level drop in the RPV enabled the steam to enter the EC tubes (as depicted on the right side of Fig. 2). The contact of saturated steam with cold tubes walls leads to heat exchange and condensation of steam. The power of the EC calculated on the basis of measurements is presented in the figure below together with these computed by the models. The dashed lines indicate $\pm 15 \%$ deviations from the measurement curve.

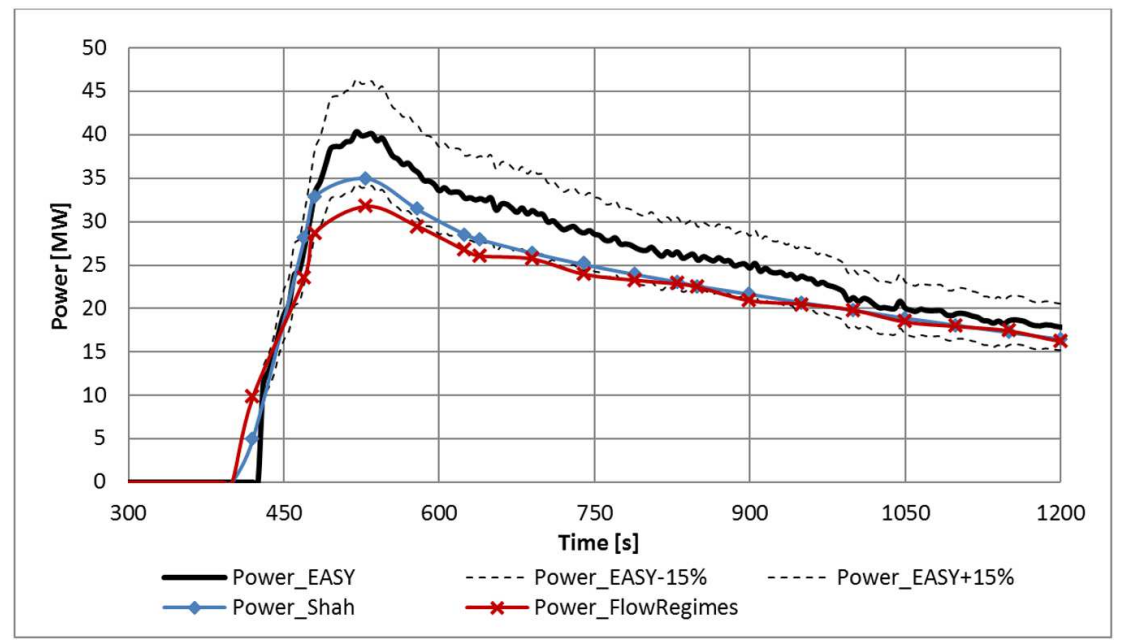

Figure 9: EC Power.

Figure 9 shows that the model on the basis of Shah correlation does not exceed $15 \%$ error during the whole simulation. The flow regimes based model shows larger discrepancy at the beginning of the transients. Both models show better accuracy with decreasing pressure variation.

Regarding the fluid temperature, two points were chosen to compare measurements with calculations. The first measurement point was situated ahead of the angulation of the EC pipes, i.e., at the $x=4.423 \mathrm{~m}$, where $x$ is the longitudinal coordinate of the pipe. Corresponding calculation point was $x=4.32 \mathrm{~m}$. The discrepancy of around $10 \mathrm{~cm}$ is caused by location of thermocouple during the test and nodalization of the models. In order to decrease this discrepancy, 4 times denser nodalization would have to be applied which would strongly influence calculation time, but would not lead to improvement of comparison quality. The second measurement point was located at $x=5.756 \mathrm{~m}$, i.e., at the bottom part of angulation of the pipe. Figure 10 shows positions of thermocouples arrangement at EC tube at INKA. 


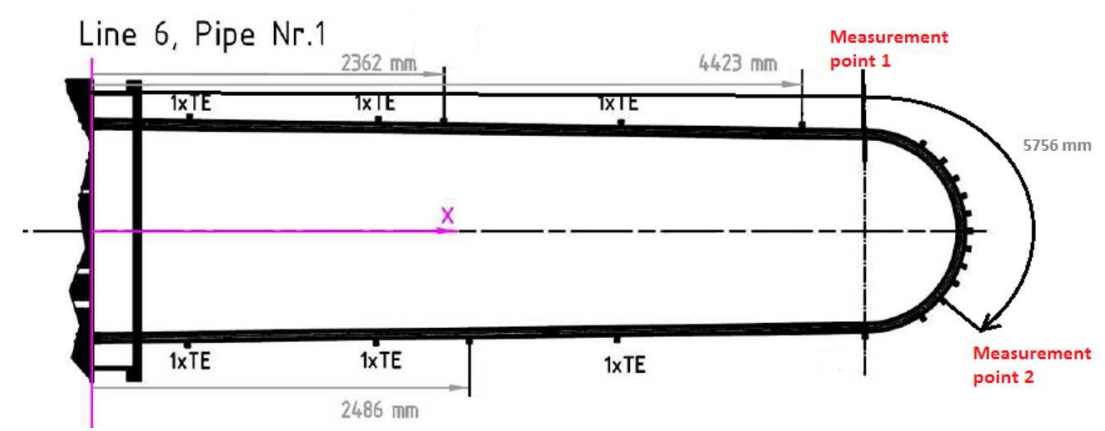

Figure 10: Positions of thermocouples chosen for comparison.

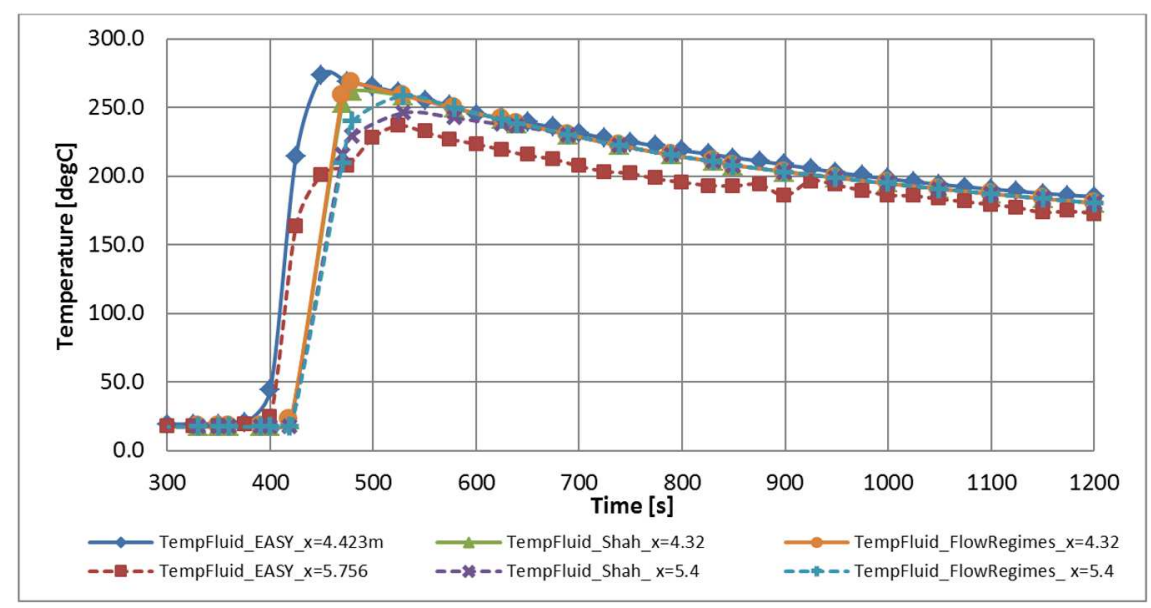

Figure 11: Fluid temperatures.

Figure 11 shows temperatures measured at both locations and calculated values at corresponding positions. It indicates that around 4.3 meters from the EC inlet, the flow is still a two-phase mixture at the saturation temperature. This is both, in the case of calculation and measurements. Temperature calculated at the second point is in both models larger than the measured value. This comes obviously from the discrepancy of calculated and measured heat transfer and partly due to relatively large distance of $0.35 \mathrm{~m}$ between measurement and calculation points. Figure 11 shows also that measured temperature at the second position reaches saturation temperature at around $900 \mathrm{~s}$. This is caused by significant depressurization and corresponding saturation temperature drop. 
Considering the wall temperature, due to the falling water film and stratification, significantly different values were measured at the upper and bottom wall of the tube. Therefore, two measurements are presented in the picture below. Both come from the part of EC ahead of the angulation, but one represents the upper part of the wall, and the second the bottom part. Since the water film at the bottom part of the tube is thicker, the heat transfer at this part of the tube is lower, and so is the temperature. Figure 12 shows measured and calculated values.

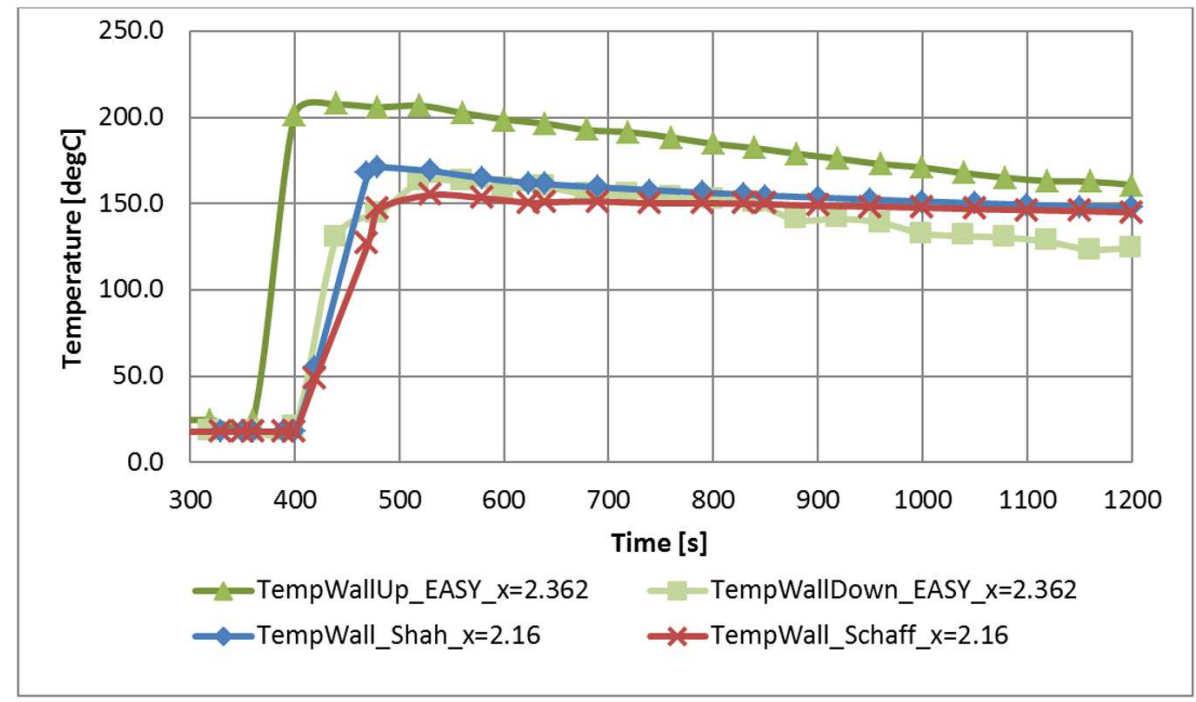

Figure 12: Inner wall temperatures.

Since the wall temperature in both models was calculated without distinction of the top and bottom side, there is a significant discrepancy between measured and calculated values. At the beginning of the transient, calculated values are close to temperature of the bottom part of the tube. With proceeding depressurization of the system, the calculated temperature becomes closer to the upper part of the tube. The issue of modelling of condensation in horizontal tubes with distinction between upper and bottom parts of the tube will be the subject of the future work.

An important factor in modelling of the EC is the FPV, i.e., water temperature in the vessel and the heat transfer coefficient at the secondary side. Figure 13 shows measured and calculated temperatures of the water at the secondary side. 


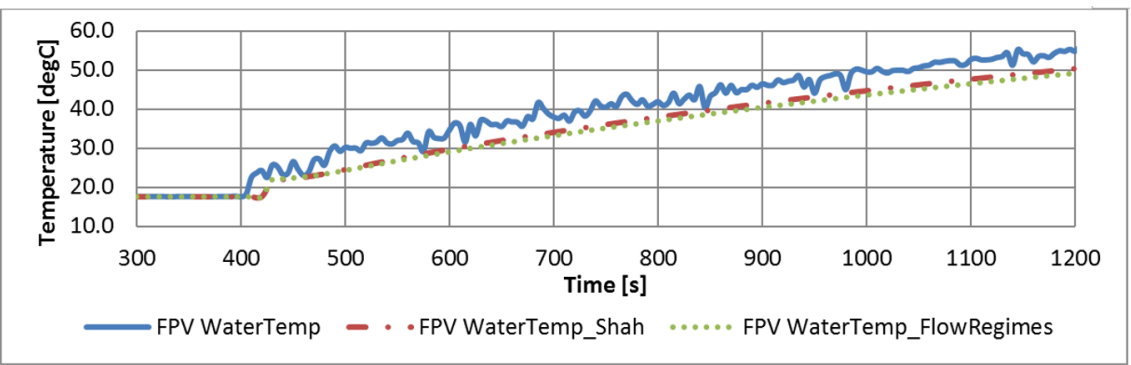

Figure 13: FPV water temperatures.

As it was assumed, the water temperature stays below the evaporation point, particularly if we consider the fact of pressure increase in the dry well due to the steam release during LOCA.

Although the proper measurements are not available, it is worth to have a look at some other values obtained from simulations. These values are void fraction and heat flow rates in particular volumes. Figure 14 shows the void fraction distribution along the pipe in a function of time.

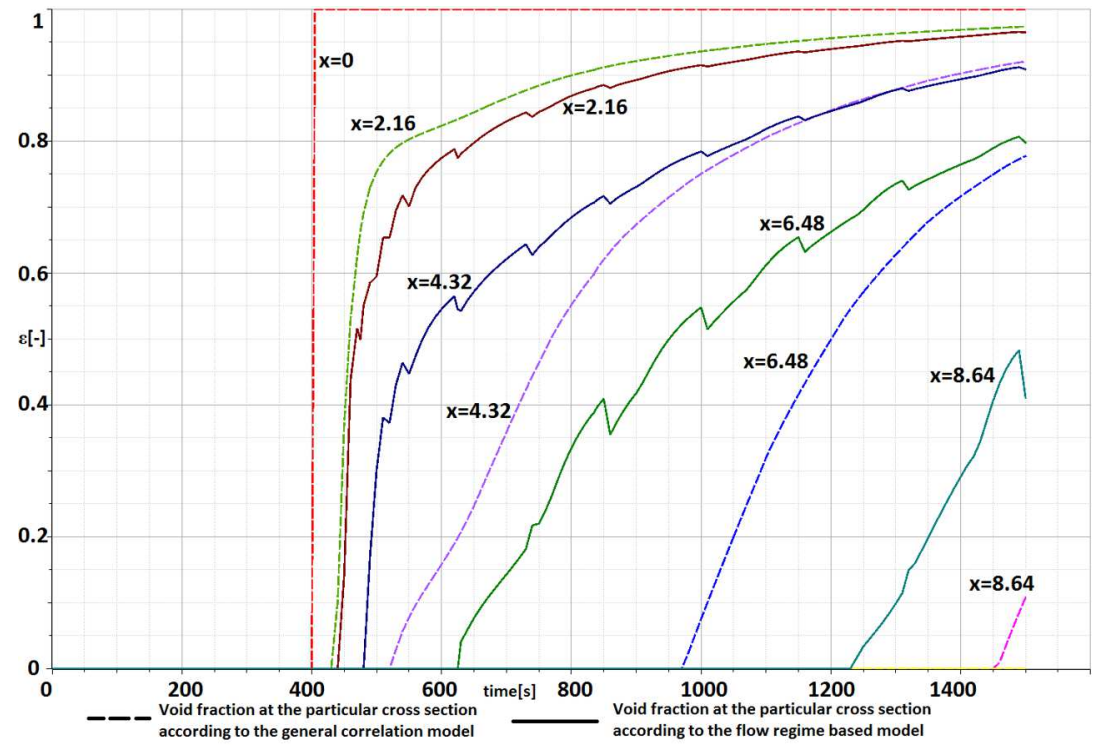

Figure 14: Void fraction distributions.

In Fig. 14, dashed lines depict void fractions at particular cross sections calculated with the general correlation model. The solid lines show void 
fractions at the same points according to the flow regime based model. The differences between model become large as the void fractions have small values. They reach, however, very close values as the pressure change with time becomes lower.

The values of heat flow rates presented in Fig. 15 are negative because the heat transfer proceeds from the fluid to the outside - to the FPV in this case. Heat flow rates distribution along the tube shows clearly different origins of the models. The curves calculated with flow regime based model have much more jerky course. This comes from switching between correlations. As it could have been predicted from previous analysis the values calculated according to general correlation are larger, and more stable.

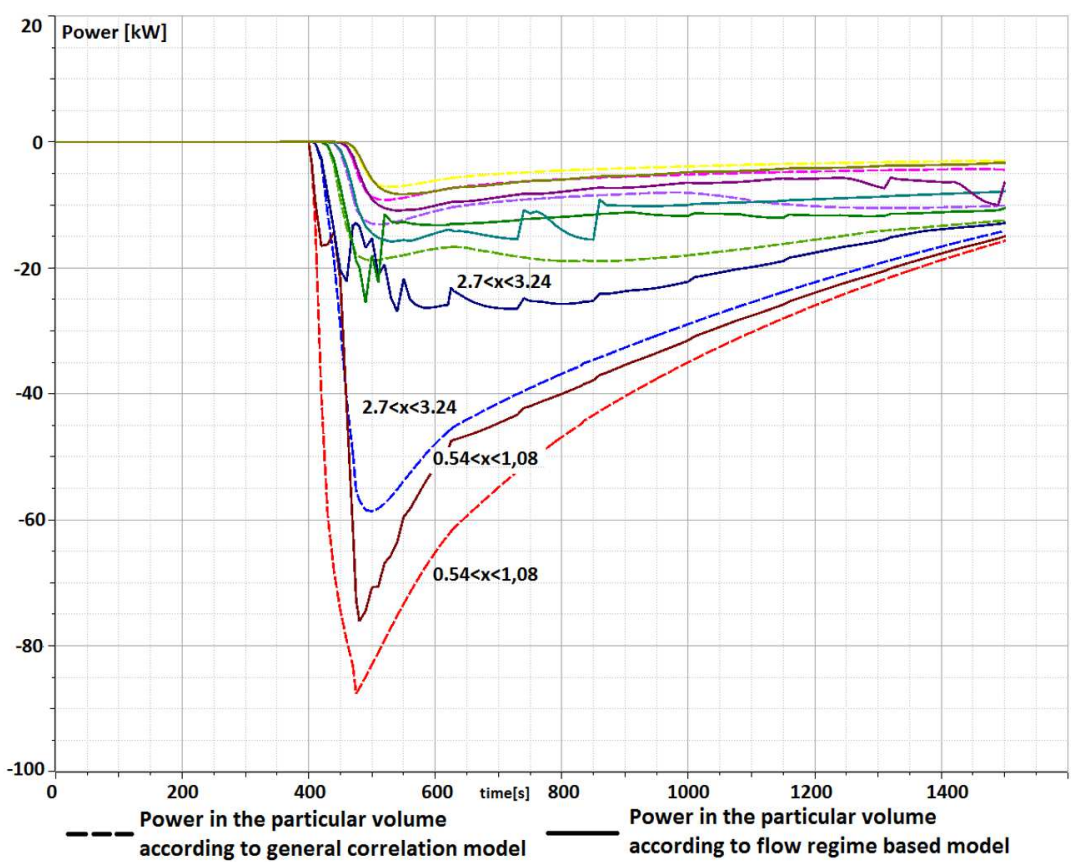

Figure 15: Heat flow rates in volumes.

\section{Conclusions and outlook}

Two different approaches for modelling of condensation in horizontal tubes have been investigated and implemented with utilization of object-oriented 
Modelica language and OpenModelica environment. The aim of this work was investigation, verification and comparison of performance of models applied with usage of open-source OpenModelica environment in order to draw conclusions considering their reliability in modelling of passive safety systems. The main conclusions are:

- both models calculate correctly the mass flow rates at the inlet to the tubes,

- since the flow regime based model switches between different heat transfer coefficient correlations, significant peaks of heat flow rates and void fractions were observed,

- these peaks may lead to discrepancies of parameters values and instabilities of simulations,

- general correlation based model is more stable, requires less computation time and gives better results;

- due to thinner film layer at the upper wall part of the tube, the wall temperature is significantly higher in this region which is not taken into account in the models,

- further work on EC modelling will be performed with consideration of distinction between upper and bottom parts of the tubes.

Received 29 September 2017

\section{References}

[1] IAEA, Power Reactor Information System, https://www.iaea.org/PRIS/home.aspx

[2] Drescher R., Wagner T. And Leyer S.: Passive BWR integral LOCA testing at Karlstein test facility INKA. VGB PowerTech, 5 (2014), 33-37.

[3] Modelica website www.modelica.org

[4] OpenModelica website www.openmodelica.org

[5] Schaffrath A., Hicken E.F., Jaegers H. and Prasser H-M.: Operation conditions of the emergency condenser of the SWR1000. Nucl. Eng. Des. 188(1999), 3, 303-318.

[6] Schaffrath A., Krüssenberg A., Fjodorow A., Gocht U., Lischke W.: Modeling of condensation in horizontal tubes. Nucl. Eng. Des. 204(2001), 1-3, 251-265.

[7] VDI Heat Atlas, Second Edition. Springer-Verlag Berlin Heidelberg 2010.

[8] Nusselt W.: Oberflächenkondensation des Wasserdampfes. Zeitschr. Vereins Deutsher Ingenieure 27(1916), 541-546, 569-575. 
[9] Tandon T.N., Varma H.K., Grupta C.P.: A new flow regimes map for condensation inside horizontal tubes. J. Heat Transfer 104(1982), 4, 763-768.

[10] Soliman E.N.: The mist-annular transition during condensation and its influence on the heat transfer mechanism. Int. J. Mutiphas. Flow 12(1986), 2, 277-288.

[11] Grimley S.S.: Liquid flow conditions in packed towers. Trans. Inst. Chem. Eng. 23(1945), 228-235.

[12] Kutateladse S.S.: Fundamentals of Heat Transfer. Edward Arnold, 1963.

[13] Kosky P.G., Staub W.F.: Local condensing heat transfer coefficient in the annular flow regime. AICHE J. 17(1971), 5, 1037-1043.

[14] Jaster H., Kosky P.G.: Condensation heat transfer in a mixed flow regime. Int. J. Heat Mass Tran. 19(1976), 1, 95-99.

[15] Breber G.W., Palen J.W., Taborek J.: Prediction of horizontal tubeside condensation of pure components. Trans. ASME J. Heat Transfer 102(1980), 3, 471-476.

[16] Sieder E.N., TAte G.E.: Heat transfer and pressure drop of liquids in tubes. Ind. Eng. Chem. 28(1936), 12, 1429-1435.

[17] Sнан M.M.: A general correlation for heat transfer during film condensation inside pipes. Int. J. Heat Mass Tran. 22(1979), 4, 547-556.

[18] Bergles A.E.: The determination of forced-convection surface boiling heat transfer. J. Heat Transfer 86(1964) 3, 365-372.

[19] Churchill W., Chu H.H.S.: Correlation equations for laminar and turbulent free convection from a horizontal cylinder. Int. J. Heat Mass Tran. 18(1975), 1049-1053.

[20] Mikielewicz D., Andrzejczyk R.: Comparative study of flow condensation in conventional and small diameter tubes. Arch. Thermodyn. 33(2012), 2, 67-83 DOI: 10.2478/v10173-012-0011-2 